\title{
A Study of the Base Pressure Distribution of a Slender Body of Square Cross-Section
}

\author{
Richard R. Mitchell" and M. Byron Webb* \\ University of Texas at Arlington, Arlington, Texas, 76019 \\ Jennifer N. Roetzel ${ }^{\dagger}$ \\ Vought Aircraft Industries, Dallas, Texas, 75211 \\ Frank K. Lu* \\ University of Texas at Arlington, Arlington, Texas, 76019 \\ and \\ J. Craig Dutton ${ }^{\S}$ \\ University of Illinois at Urbana-Champaign, Urbana, Illinois, 61801
}

\begin{abstract}
A low-speed wind-tunnel investigation of a slender body of square cross-section was conducted to determine the effect of boattail geometry on the base pressure coefficient. The data were obtained over an angle-of-attack range of 0 to 8 degrees. Surface flow patterns were visualized using tufts. An exploratory numerical modeling effort was also performed. The base pressure showed the expected decrease from top to bottom as the body angle of attack was raised. The base pressure coefficient showed a rapid rise when the angle of attack increased past $4 \mathrm{deg}$.
\end{abstract}

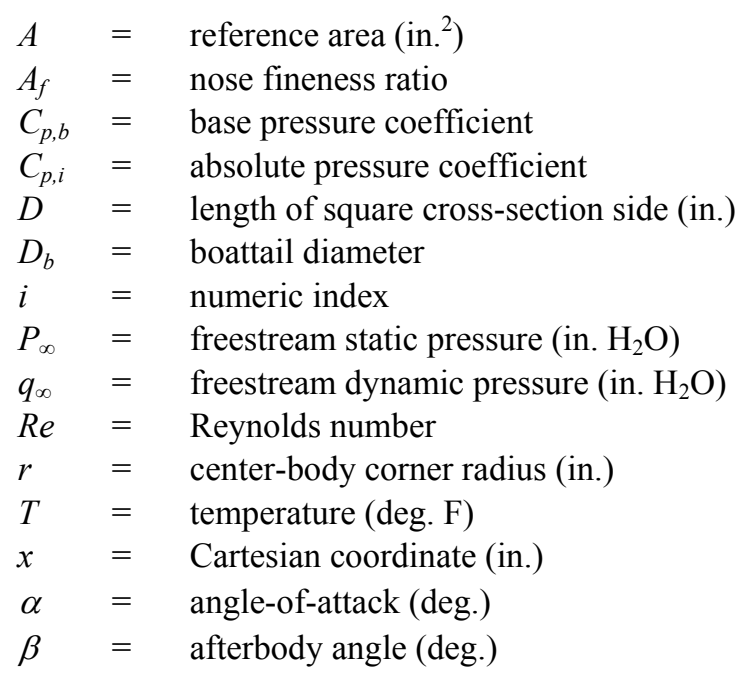

\section{Nomenclature}

*Graduate Research Associate, Aerodynamics Research Center, Department of Mechanical and Aerospace Engineering, Box 19018, Student Member AIAA.

${ }^{\dagger}$ Structural Design Engineer, 787 Structures Design, 9314 West Jefferson Boulevard, M/S 194-30, Member AIAA.

* Professor and Director, Aerodynamics Research Center, Department of Mechanical and Aerospace Engineering, Box 19018, Associate Fellow AIAA.

${ }^{\S}$ Professor and Chair, Department of Aerospace Engineering, 306 Talbot Laboratory, MC-236, 104 South Wright Street, Associate Fellow AIAA. 


\section{Introduction}

$\mathrm{M}$ UNITIONS with square or rectangular cross-section have better volumetric efficiency than conventional munitions of circular section; such configurations have been the subject of continued interest. ${ }^{1-9}$ For a bibliography of earlier work, see Ref. 10. Most of the existing literature is concerned with the aerodynamics of such shapes which are complicated by the lack of axial symmetry. One aspect that had not been well investigated is the afterbody shape for minimum base drag. This paper reports an exploratory study of the base pressure coefficient of a body with a square cross-section. The experimental study is complemented by numerical modeling.

\section{Wind Tunnel Facility}

The experimental data were acquired in a closed circuit, low-speed wind tunnel with a closed test section. The test section is $61 \mathrm{~cm}$ high, $91 \mathrm{~cm}$ wide and $190 \mathrm{~cm}$ long $(24 \mathrm{in} . \times 36$ in. $\times 75$ in.). The tunnel has a continuously variable speed capability from zero to approximately $50 \mathrm{~m} / \mathrm{s}(160 \mathrm{ft} / \mathrm{s})$. At the maximum operating condition, the tunnel is capable of obtaining a unit Reynolds number of $3 \mathrm{million} / \mathrm{m}$ ( $1 \mathrm{million} / \mathrm{ft})$.

For the experiments, the tunnel was monitored by two Omega PX653 series differential pressure transducers with dynamic ranges of 0-10 and 0-5 in. $\mathrm{H}_{2} \mathrm{O}$. These transducers have an accuracy of one percent of full scale, which corresponds to an uncertainty of \pm 0.05 in. $\mathrm{H}_{2} \mathrm{O}$. The data were acquired by a National Instruments PCI-MIO16E-4 DAQ with a LabVIEWTM interface running on an Intel Pentium-III ${ }^{\mathrm{TM}}$ class, Windows XPTM workstation. The transducers were calibrated against a Meriam Model 40HE35 slant tube manometer.

\section{Model}

The test article comprised of five major components as shown in Fig. 1. The colors in the figure are used to distinguish the major model sections, comprising of the nose, the centerbody, the boattail and the base. The overall length of the model was $783.7 \mathrm{~mm}$ (30.853 in.) The nose cone was manufactured from acetal copolymer, which was selected for its ease of machining. The rest of the model was constructed of 6061-T6 aluminum. The model was mounted such that the sides were horizontal and vertical.

The sharp pointed nose pointed toward the flow, which is directed from right to left in the Fig. 1. The tangent ogive nose had a fineness ratio of 1.59. The base of the nose was a $101.6 \mathrm{~mm}$ square (4 in.). The nose cone contour was designed to enclose a large portion of the strut mount, thus minimizing any unnecessary disturbances to the external flow field. The centerbody had a $101.6 \mathrm{~mm}$ (4 in.) square section and it was $304.8 \mathrm{~mm}$ (12 in.) long. The corners of the square section were all sharp. A static pressure tap was located at the geometric center of each surface of the centerbody.

The boattail section had a contraction ratio of $D_{b} / D=0.798$, which is defined as the diameter of the base section over the hydraulic diameter of the boattail section. This corresponded to an afterbody angle of $9 \mathrm{deg}$. and an overall length of $185.3 \mathrm{~mm}$ (7.296 in.). Fifteen pressure ports, spaced at $11.56 \mathrm{~mm}(0.455 \mathrm{in}$,) were located along the center of the bottom face of the boattail -

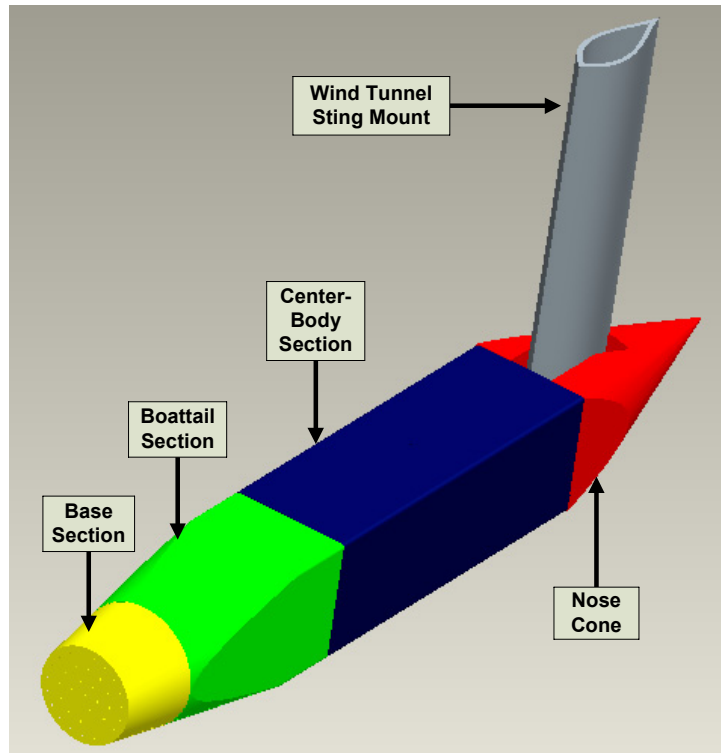

Figure 1. Schematic of assembled model.

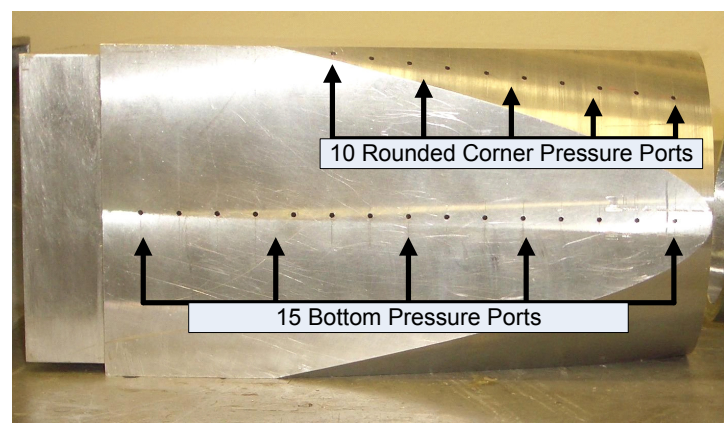

Figure 2. Boattail pressure ports. each having a diameter of $1.59 \mathrm{~mm}$ (0.0625 in.). Ten additional pressure ports, of the same diameter and spacing, were placed along the bottom, rounded corner of the boattail, oriented 45 deg.. with respect to the model centerline (Figure 2). These ports were located on the bottom of 
the boattail to obtain measurements that were least disturbed by the mounting strut. The model base section boundary was defined by the extrapolation of the afterbody angle down to a diameter of $81 \mathrm{~mm}$ (3.19 in.).

For the base pressure port arrangement, a radial pattern was used such that there was one port at the geometric center of the base, and at radii of $11.7,23.1$ and $34.8 \mathrm{~mm}(0.46,0.91$ and 1.37 in.) giving 6,13 and 19 equally spaced ports, respectively. Two additional sets of four ports each extended the pair of afterbody tap traces to the base of the model. The model was mounted in the test section by connecting it to a slender streamlined strut extending from the ceiling of the test section $25.5 \mathrm{~mm}(1 \mathrm{in}$.) fore of the windward edge of the centerbody.

The afterbody section of the missile model was designed to be modular, so that the main body of the model may be reused in future experiments with alternative boattail geometries. A boundary layer transition strip was attached on the model nose, $63.5 \mathrm{~mm}$ ( $2.5 \mathrm{in}$.) behind the cone tip as measured along the model surface per Ref. 11. The transition strip was an annular region of \#37 sand grit, $1.6 \mathrm{~mm}$ (0.0625 in.) wide.

\section{Test Conditions}

Experiments were conducted at zero yaw and roll angles, for the angle-of-attack range of 0 to 8 deg. with the wind tunnel set at its maximum operating speed. During each run, the model referenced Reynolds number (based upon the side length of the center-body section) decreased slightly from $9.47 \times 10^{5}$ to $8.95 \times 10^{5}$ due to an increase in the tunnel freestream temperature. A typical wind tunnel model setup is shown in Fig. 3 - note the digital protractor in the photograph being used for determining the angle-of-attack. The uncertainty of the angle measurement was estimated to be $\pm 0.1 \mathrm{deg}$.

Measurements were taken using a bank of 41 brass gang valves. The valves were manually switched one by one to an Omega PX653-05PV pressure transducer. Readings from all 78 pressure ports located on the test model were taken while the wind tunnel was at the maximum speed setting. All the surface pressure data along with test section temperature, atmospheric pressure, and wind tunnel static pressures were collected via a LabVIEW interface.

Other than the above measurements, tuft flow visualization was also attempted. Size T3 cotton threads were affixed to the sides of the missile model using Scotch ${ }^{\mathrm{TM}}$ tape to avoid clogging of the surface pressure ports with liquid adhesive. The resulting flow field was then photographed through the Plexiglas ${ }^{\mathrm{TM}}$ test section door using a Nikon D40 digital camera with ambient fluorescent lighting.

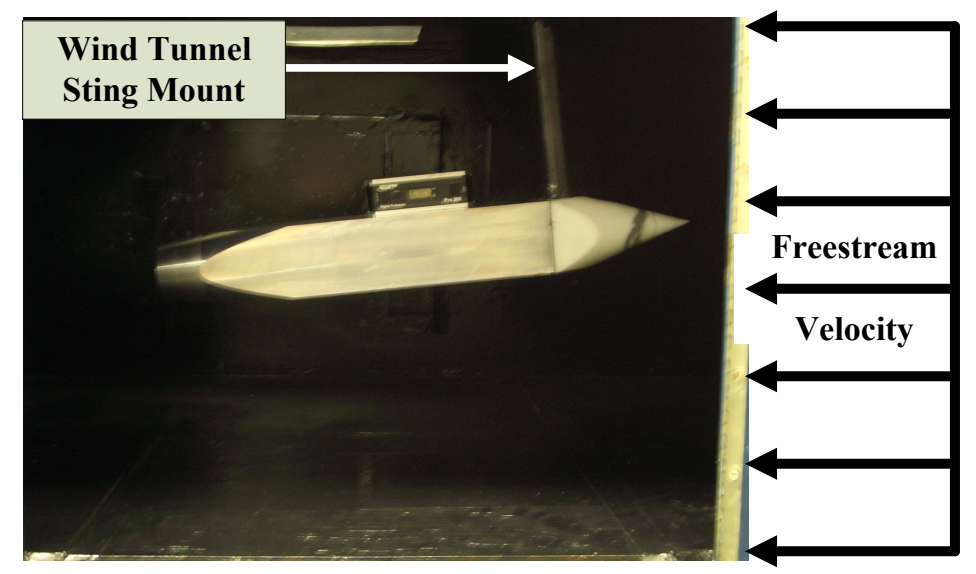

Figure 3. Typical tunnel model setup.

\section{Discussion of Results}

The primary results obtained from the experiments were the individual base port pressure measurements at different angles of attack. These individual pressure measurements were then reduced into contour plots of the base pressure coefficient and integrated numerically to yield an area-weighted, average base pressure coefficient for the given freestream tunnel conditions.

\section{A. Base Pressure Variation Results}

The variation of the missile base pressure with angle-of-attack is shown in Figs. 4-11 in terms of an "absolute" pressure coefficient 


$$
C_{p, i}=\left\|\frac{P_{i}-P_{\infty}}{q_{\infty}}\right\|
$$

In Eq. (1), $P_{i}$ is the static pressure at the $i^{\text {th }}$ location on the model base, $P_{\infty}$ is the test section static pressure, and $q_{\infty}$ is the test section dynamic pressure. Note that for Figs. 4-8, the view shown is as the base would appear when looking upstream.

For a 0 deg. angle-of-attack, the result shown in Fig. 4 is what would be expected for an incompressible base flow over an axisymmetric slender body, that is, a relatively uniform base pressure distribution. At first glance this may not be evident, as several different contour intervals are shown. Note, however, that the difference between the maximum and minimum contour level is 0.05 , which is within the uncertainty bounds of the differential pressure transducers.

As the angle-of-attack is increased, the effects of a lifting body become more pronounced in the base pressure contours. Beginning with Fig. 5, at an angle of attack of 2 deg., relatively high absolute pressure coefficients (corresponding to a more negative $C_{p}$ value in the traditional sense) begin to emerge at the top of the base. This trend continues with increasing angle of attack until, at the maximum tested angle of attack of 8 deg., the upper portion of the base is at a much lower relative pressure than the lower portion.

One result, however, may be taken from a more thorough consideration of Figs. 8-11. Note that the developing low pressure zones on the upper portion of the base area are not symmetrical with respect to the $y$-axis. For a yaw and roll angle of 0 deg., we might expect to see this symmetry reflected in the flow field. From the data, however, the model appears to have a slight yaw with respect to the freestream. This can be attributed to the nature of the closed-circuit tunnel that imparts a small yaw of $0.3 \mathrm{deg}$. from the right of the tunnel axis as looking upstream (Figs. 4-8). Additionally, it should be mentioned that a $0.3 \mathrm{deg}$. positive angle-of-attack flow angularity was measured in the empty test section.

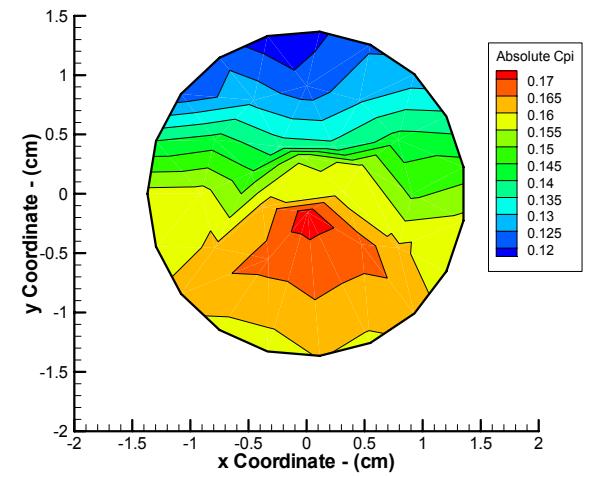

Figure 4. Base pressure contours for $\alpha=0^{\circ}$.

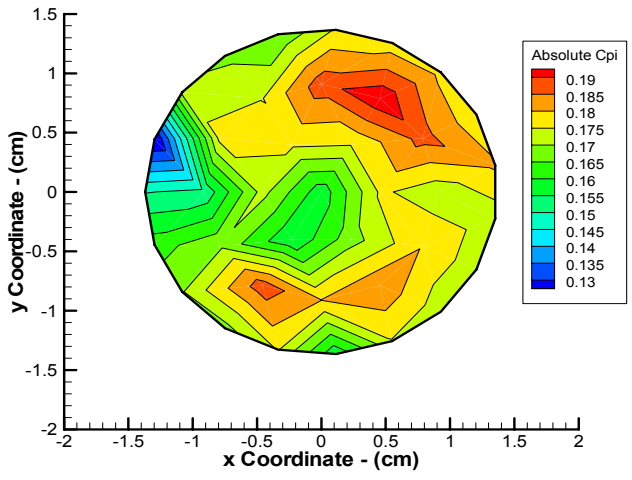

Figure 5. Base pressure contours for $\alpha=2^{\circ}$.

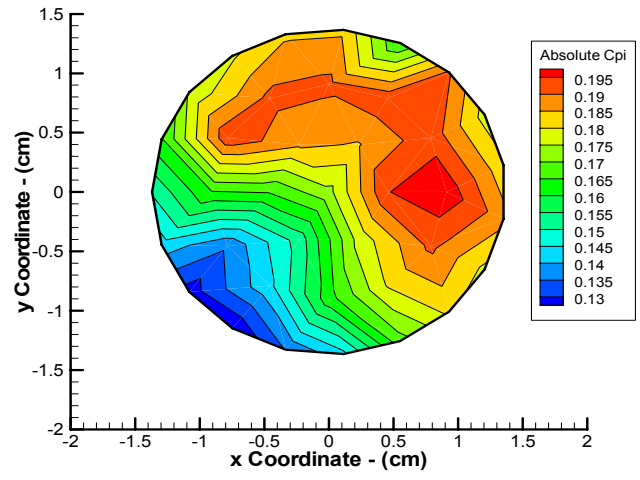

Figure 6. Base pressure contours for $\alpha=4^{\circ}$. 


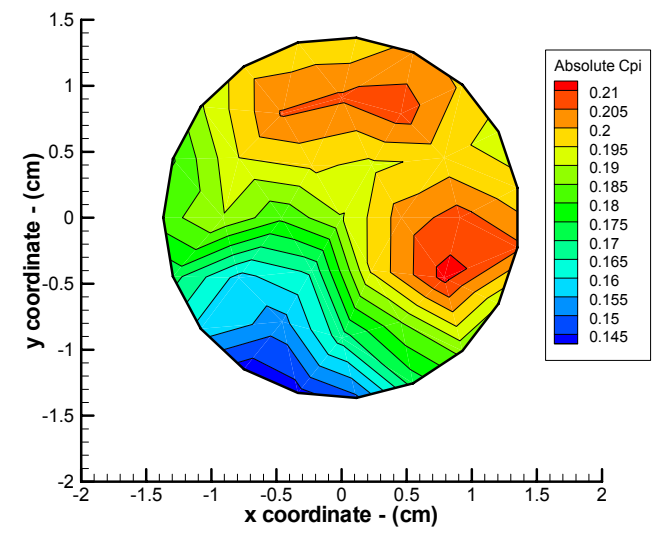

Figure 7. Base pressure contours for $\alpha=6^{\circ}$

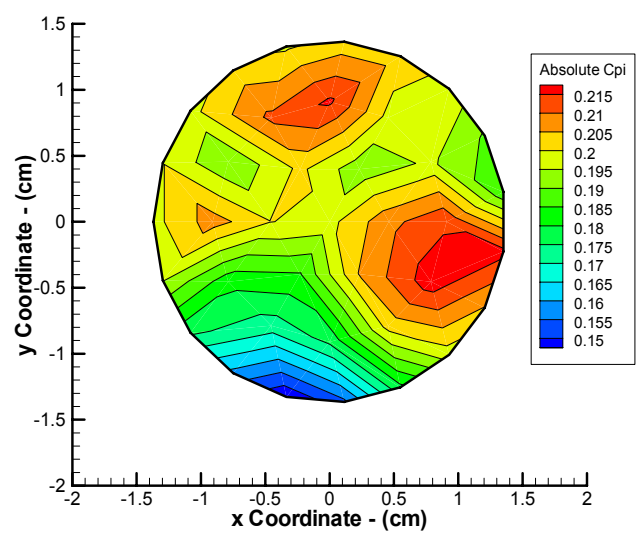

Figure 8. Base pressure contours for $\alpha=8^{\circ}$.

\section{B. Base Pressure Coefficient Variation}

With the individual base pressure coefficients determined, the overall base pressure coefficient may be determined in terms of an area weighted summation of the individual base pressure coefficients. This may be expressed as:

$$
C_{p, b}=\sum_{i=1}^{n} C_{p, i} \frac{A_{i}}{A_{b a s e}}
$$

where $n$ is the number of base pressure ports, $A_{i}$ is the effective area of the $i^{\text {th }}$ port, and $A_{\text {base }}$ is model base area (approximately $8.00 \mathrm{in}^{2}$ ).

The effective area for the $i^{\text {th }}$ pressure port is approximated directly from Fig. 9. Using the geometric dimensions of the model base, the entire base area may be divided into annular segments, with the exception of the central port, which has a circular base area. All variables in Eq. (2) are now known and may be summed over the base area to give the overall base pressure coefficient.

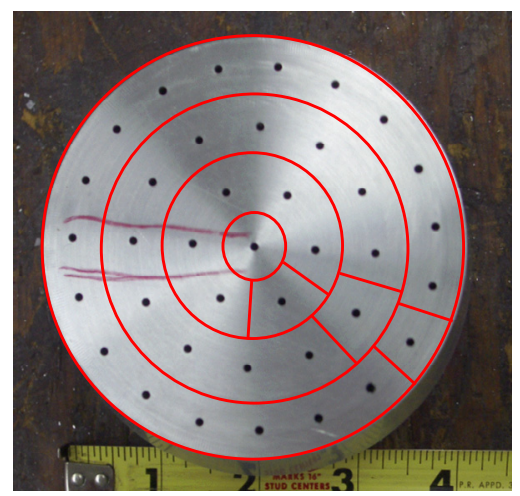

Figure 9. Schematic of base area approximation.

This methodology is then repeated for each angle-of-attack orientation of the missile model to yield the overall base pressure coefficient as a function of $\alpha$. The results of this analysis are shown in Fig. 10. Note that the variation of the overall base pressure coefficient with angle-of-attack bears a striking resemblance to the "drag-bucket" characteristic of many laminar-flow airfoils.

It is important to keep in mind that the flow interference arising from the "sting" mount is expected to be significant at high angles-of-attack. However, the primary concerned here is the relative effects of afterbody 
geometries on the overall base pressure coefficient. Thus, in the relative sense, the "sting" interference may be taken as a tare value without further correction of the gathered experimental data.

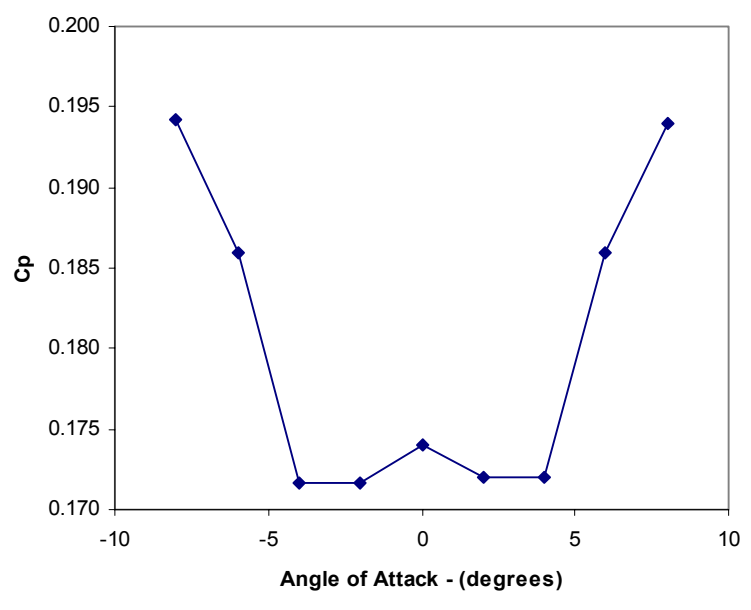

Figure 10. Overall base pressure coefficient variation with angle-of-attack $\alpha$.

\section{Tuft Flow Visualization}

Tuft flow visualization was employed to gain further insight into the missile body flow field. The tufts do not show any indication of flow separation. Sample photographs of the "tuft" visualization tests are shown in Figs 11 and 12. For all angles of attack considered, (i.e., \pm 8 deg.), the tufts were all pointed downstream with a small amount of fluttering. The only tufts that showed some fluttering were the first two immediately downstream of the "sting" mount - indicating the suspected perturbing wake discussed in Section VI. The absence of flow separation was not surprising due to the small range of angle of attack.. References 2 and 3 indicate that separation occurs at angles of attack of 25-30 deg for slender missiles of square cross-section, beyond the present test range.

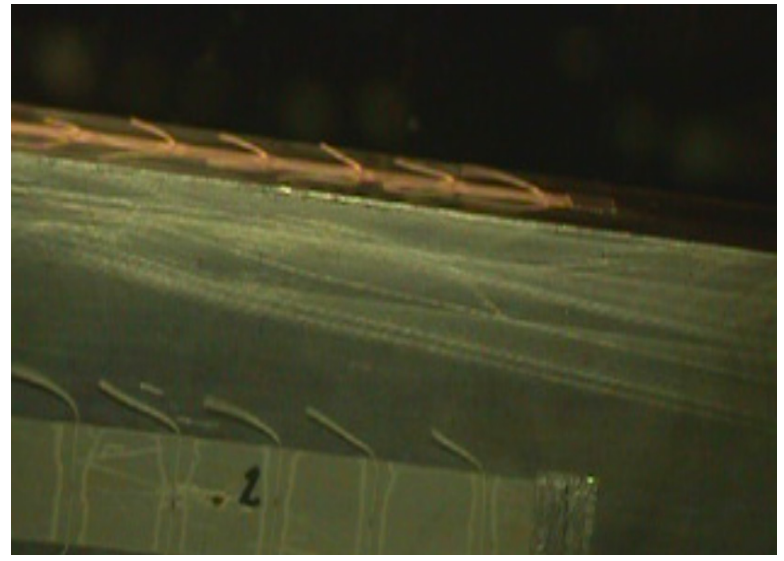

Figure 11. Tuft visualization for $\alpha=0^{\circ}$ (flow direction from right to left).

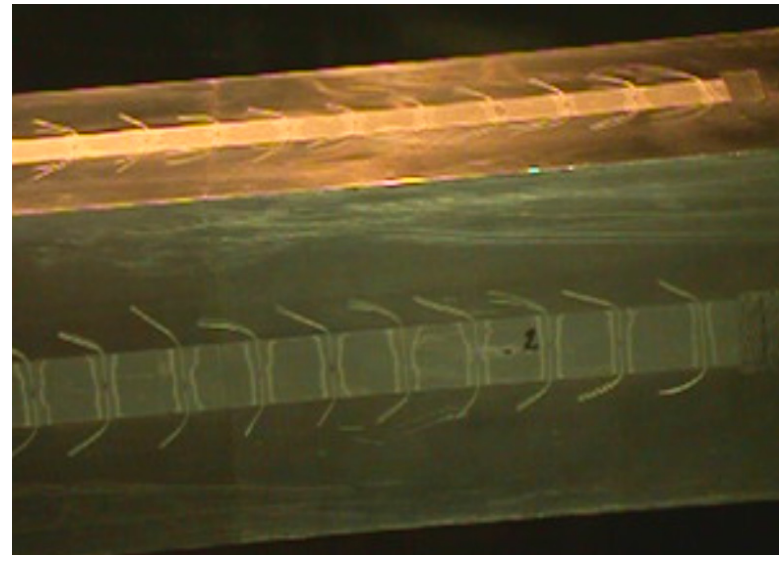

Figure 12. Tuft visualization for $\alpha=7^{\circ}$ (flow direction from right to left).

\section{Numerical Analysis}

The software package ANSYS CFX was used to supplement the experimental data. The simulation was run on a Pentium 4HT, $3.39 \mathrm{GHz}$ processor with 3.25 gigabytes of SDDR RAM. Each run yielded the same results for the pressure, velocities and turbulence. The refined mesh, with over 400,000 elements, was used to construct the figures. The outer control volume, which included the test section inlet, outlet and walls, measured 24 in. high, 24 in. wide and $72 \mathrm{in.} \mathrm{long.} \mathrm{The} \mathrm{slender} \mathrm{body} \mathrm{geometry} \mathrm{used} \mathrm{in} \mathrm{the} \mathrm{analysis} \mathrm{was} \mathrm{imported} \mathrm{into} \mathrm{ANSYS} \mathrm{Workbench}$ from Pro/ENGINEER solid modeler with all of the same dimensions as the experimental model. A tetrahedral mesh 
for the surface and volume elements was generated through CFX-Mesh. Boundary conditions were set for the model in CFX-Pre. Inlet velocity conditions were set to $100 \mathrm{deg}$. F, with a unidirectional velocity of $100 \mathrm{mph}(146.67 \mathrm{ft} / \mathrm{s})$ and a reference pressure of $1 \mathrm{~atm}\left(406.78 \mathrm{in} . \mathrm{H}_{2} \mathrm{O}\right)$. The outlet back pressure was set to zero to ensure no upstream disturbances. The walls of the wind tunnel were set to free-slip conditions to negate near-field effects, such as wall turbulence. In addition, the surrounding enclosure walls were set to an isothermal, adiabatic surface of $100 \mathrm{deg}$. F. The surface of the missile was set to a no-slip condition.

The fluid domain used for the simulation was incompressible and isothermal. A standard $k$ - $\omega$ turbulence model was selected. All other default solver values were retained. Once the model is fully constrained, the solver is initiated. The actual time to solve the flow field depended directly upon the number of elements in the mesh. The results and figures shown are extracted from the model with the highest number of elements, in order to ensure that boundary layer flow over the model is accurately represented.

A plane is cut down the center of the model to show the pressure, velocity and turbulence of the model. The base pressures shown in Fig. 13 are local to the geometry. The computed body pressures are used to find the base pressure coefficient. Figures 14-16 shows the turbulence eddy frequencies, pressures and velocities localized at the base area of the missile.

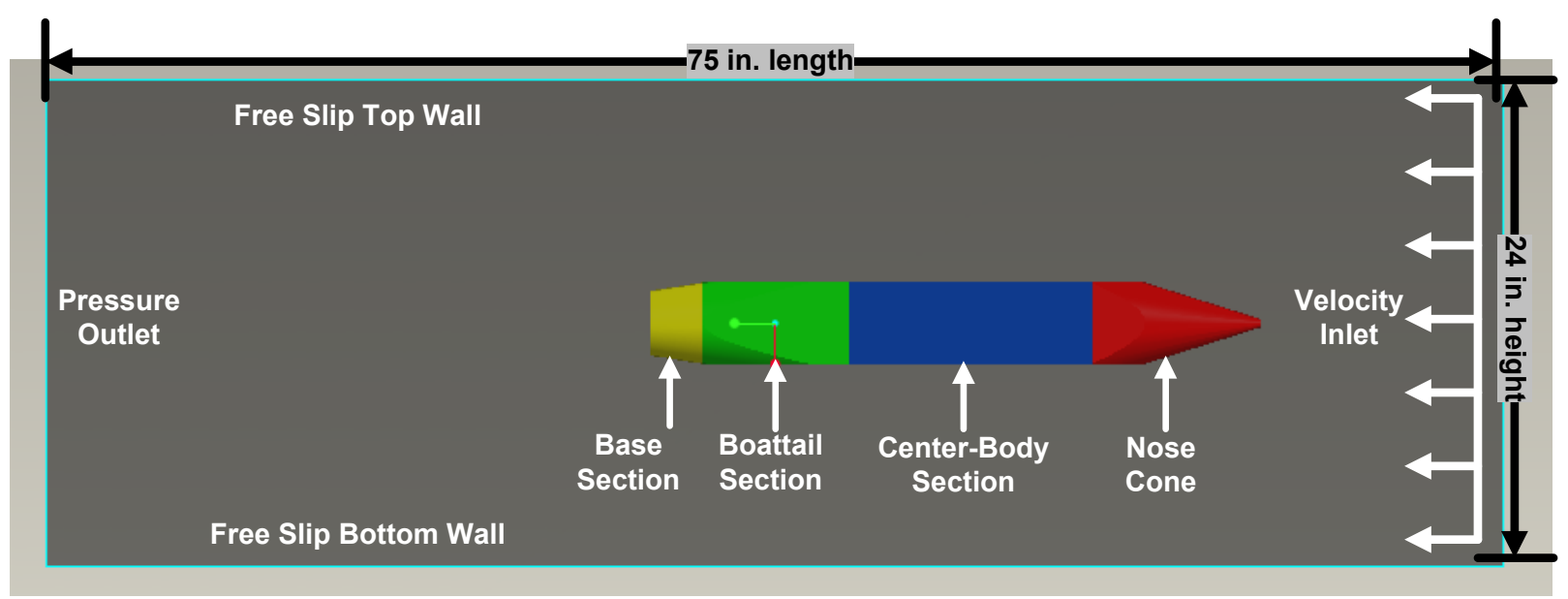

Figure 13. Computational domain with square cross-section model.

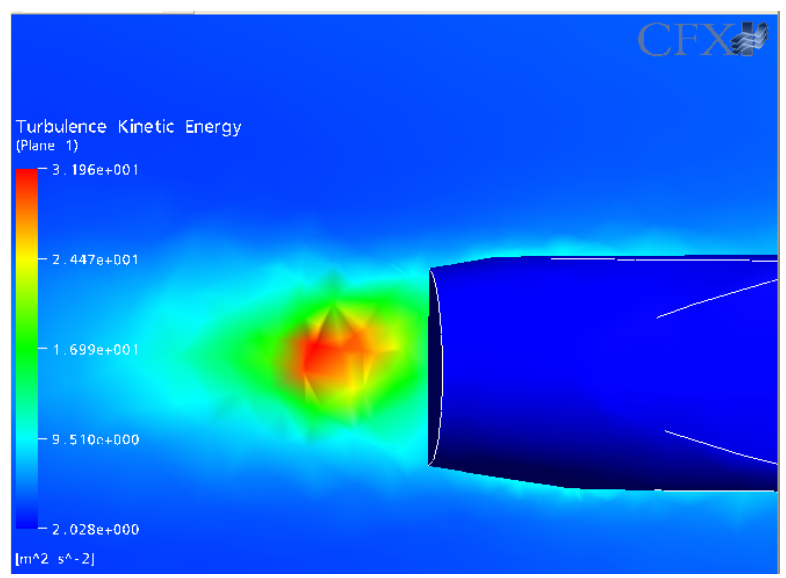

Figure 14. Turbulence contour plot. 


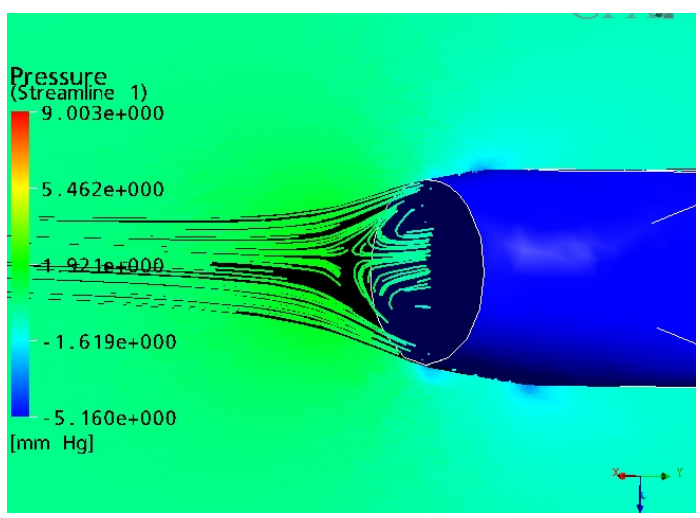

Figure 15. Pressure contour plot.

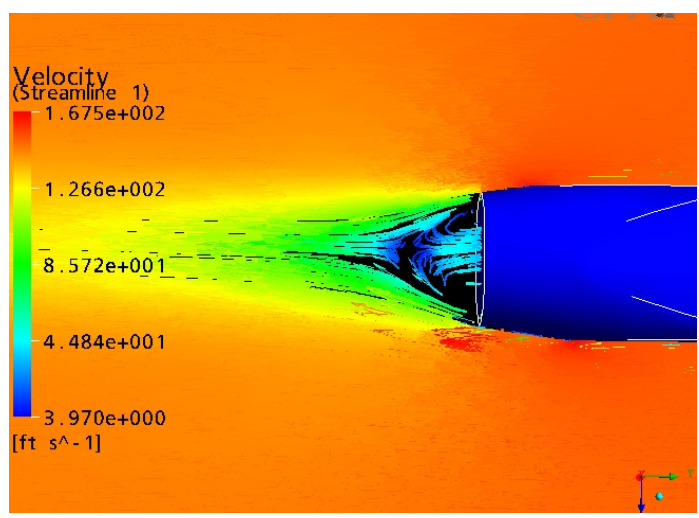

Figure 16. Velocity contour plot.

The initial computational simulations show similarities between the wind tunnel data and tuft flow visualization. Estimated $C_{p, i}$ values from the streamlines in Fig. 15 roughly correspond measurements from wind tunnel testing. However, exact data point locations corresponding to the pressure ports on the base and boattail wind tunnel model were not measured.

\section{Conclusions}

The variation of base pressure distribution and overall base pressure ratio with angle-of-attack have been presented for a baseline missile body of square cross-section. The primary variable of interest, the overall base pressure ratio, has been shown to be a strong function of the model angle-of-attack. Additionally, preliminary CFD analysis has been offered for the purposes of validating the collected experimental data.

\section{Acknowledgments}

The authors would like to express their gratitude to Mr. Rod Duke for his advice and expertise during the fabrication of the missile model. We would also like to thank Professor Don Seath for his insight. Finally, funding for this work was provided by Lockheed Martin Missiles and Fire Control, monitored by Philip Beyer.

\section{References}

${ }^{1}$ Daniel, D.C., Yechout, T.R., Zollars, G.J., "Experimental Aerodynamic Characteristics of Missile with Square Cross Sections," Journal of Spacecraft and Rockets, Vol. 19, No. 2, pp. 167-172, 1982.

${ }^{2}$ Daniel, D.C., Zollars, G.J., Yechout, T.R., "Reynolds Number Effects on the Aerodynamics of a Body with Square CrossSection," Journal of Spacecraft and Rockets, Vol. 21, No. 4, pp. 413-414, 1984.

${ }^{3}$ Jackson, C.M. and Sawyer, W.C., "Bodies with Non-Circular Cross-Sections and Bank-to-Turn Missiles," in Tactical Missile Aerodynamics: General Topics, edited by M.J. Hemsch, AIAA, pp. 365-389, Washington, DC, 1992.

${ }^{4}$ Birch, T.J. and Petterson, K., "CFD Predictions of Square and Elliptic Cross-Section Missile Configurations at Supersonic Speeds," AIAA Paper 2004-5453, 2004.

${ }^{5}$ McIlwain, S. and Khalid, M., "Computations of Square and Elliptical Section Missiles Using WIND," AIAA Paper 20045455,2004

${ }^{6}$ Mahjoob, S., Mani, M. and Taeibi-Rahni, M., "Aerodynamic Analysis of Circular and Noncircular Bodies Using Computational and Semi-Empirical Methods," Journal of Aircraft, Vol. 41, No. 2, pp. 399-402, 2004.

${ }^{7}$ Sahu, J., Silton, S.I. and Heavey, K.R., "Numerical Computations of Supersonic Flow over Non-Axisymmetric Missile Configurations." AIAA Paper 2004-5456, 2004.

${ }^{8}$ Trickey, C.M., Edwards, J.A., Shaw, S., Faminu, O. and Hathaway, W., "Experimental and Computational Assessment of the Dynamic Stability of a Supersonic Square Section Missile," AIAA Paper 2004-5454, 2004.

${ }^{9}$ Wilcox, F.J., Jr., Birch, T.J., Allen, J.M., "Force, Surface Pressure, and Flowfield Measurements on a Slender Missile Configuration with Square Cross-Section at Supersonic Speeds," AIAA Paper 2004-5451, 2004.

${ }^{10}$ Sigal, A., "Methods of Analysis and Experiments for Missiles with Noncircular Fuselages," in Tactical Missile Aerodynamics: Prediction Methodology, edited by M.R. Mendenhall, pp. 171-223, AIAA, Washington, DC, 1992.

${ }^{11}$ Barlow, J.B., Rae, W.H. and Pope, A., Low-Speed Wind Tunnel Testing, $3^{\text {rd }}$ ed., Wiley, New York, 1999. 